\title{
Opinion
}

\section{Development and Significance of "Mamin": A Child-Care Record-Keeping Mobile Application for Parents}

\author{
Makiko Oowaki, RN, MN, PhD'"; Yasuko lida, PhD²; Masafumi Koshiyama,MD, PhD' \\ 'School of Human Nursing, The University of Shiga Prefecture, Shiga, 522-8533, Japan \\ ${ }^{2}$ Tokyo Healthcare University, Tokyo, Japan
}

\section{*Corresponding author}

Makiko Oowaki, PhD

School of Human Nursing, The University of Shiga Prefecture, Shiga, 522-8533, Japan; Tel. +8I-749-28-9542; Fax: +8I-749-28-9544; E-mail: owaki@nurse.usp.ac.jp

\section{Article information}

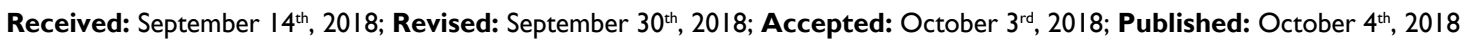

\section{Cite this article}

Oowaki M, Lida Y, Koshiyama M. Development and significance of "Mamin": A child-care record-keeping mobile application for parents. Women Health Open J. 20I8; 4(I): 8-I0. doi: 10.17I40/WHOJ-4-I26

$\mathrm{M}$ any studies ${ }^{1,2}$ have indicated that early detection, early intervention and treatment lead to a favorable prognosis for child illnesses and disabilities, the slightest signs of which, in reality, are often overlooked.

There are mobile application for screening Autisum, ${ }^{3}$ or for tracking growth of extremely preterm or extremely low birthweight infants. "Mamin" specifically records daily child development, enabling earliest screening of and intervention for developmental abnormality.

This paper is a report on our development of a childcare record-keeping mobile application known as "Mamin" and its significant roles in the early detection of latent child illnesses and disabilities.

\section{FACTORS HINDERING EARLY DETECTION AND EARLY IN- TERVENTION}

Factors hindering early detection and early intervention include the following: 1) family or other near child failing to notice signs of illness and/or disability; 2) health care workers with whom the parents consult failing to notice signs of illness and/or disability due to a lack of specialized knowledge, and 3) parents being unable to accept the illness and/or disability, which delays treatment.

\section{MEASURES PROMOTING EARLY DETECTION AND EARLY INTERVENTION}

The following three measures are proposed to facilitate early detection and early intervention:
Increase Chances for Family and/or People Around the Child to Recognize Even Slight Signs of an Illness of Disorder

For the proper detection of child disorders, careful observations of the undisguised words and actions of a child is indispensable. However, the increasing number of working couples has made it difficult for parents to observe and record their child's behavior and development in a timely manner. One way to manage this difficulty may involve the adoption of networking system, through which child-care information can be accessed via tablet or smartphone used by the parents at any time and in any place.

Encourage Parents to be as Informed as Possible about Their Child and Introduce Them to a Number of Health-Care Providers

Health-care providers are always busy and have little time to spare for individual parents. Furthermore, few parents are able to convey the necessary information to a health-care provider briefly, efficiently, and in a chronological manner. Voice and visual recordings may be a good solution to this problem. Video recordings accurately and effectively integrate and store information on a child with the parents' comments and questions.

Help Parents Accept the Signs of Illnesses and/or Disabilities in Their Children

The use of clichéd expressions by professionals to persuade parents to accept reality may, on the contrary, only reinforce parents' denial. The quickest way to ensure parents' acceptance of reality is to support parents' self-recognition and understanding. One good way to achieve this is for a professional to simply 'wait' until the parents are ready to accept reality, unless the situation is an emer- 
gency, while providing enough information for them to accurately recognize and understand the situation. The adoption of audio and visually recorded materials can be useful way to ensure that parents, others around child and health professionals are all on the same page with a common recognition of the child's disorder.

\section{CHILD-CARE RECORD-KEEPING MOBILE APPLICATION: CONSIDERATIONS UPON DEVELOPMENT}

The application "Mamin" has nine functions, as described below.

It Increases Chances for Family and/or People Around the Child to Recognize Even Slight Signs of an IIIness of Disorder all Day

Function I:The child's age (x-years and $y$-months) is readily displayed on the first screen of "Mamin": Confirmation of the child's age (x-years and y-months) urges parents to re-recognize their child's developmental state, which is indicated in accordance with the Maternal-Child Health Handbook. A reminder notice to check the child's development is displayed at certain stages of development.

Function 2: Explanatory notes can be added so that the recording is readily available as a document of the child's growth and development: The principal aim of this application is the early detection of a child's illness or disability; however, the recording itself can also be used to document the child's development. It can function as an electronic album for both healthy and afflicted children, and a paper-based album can easily be created by printing the recording.

Function 3: Information is easily shared among family members, close friends and child-care professionals: The parent can easily send informations by video or photos with an email as an attached document. The date, month and year of the recordings are recorded, and the media are saved in chronological order for easy access by professionals, whenever necessary.

Function 4:The contents are covered in accordance with the Maternal-Child Health Handbook to facilitate confirmation of their child's development: An indicator message is displayed to encourage parents to check their child's development in the MaternalChild Health Handbook at each monthly milestone of age.

Function 5:The individual recording system helps parents make a record without mixing up information:

\section{a) For cases with multiple ill and disabled children}

In some cases, a family may have more than one ill or disabled child. For example, twins may have illnesses or disabilities due to a congenital background or acquired postnatally due to birth problems. Furthermore, genetic mis-fortune may affect every birth in a family. The individual recording system assists parents in correctly making a record without mixing up information on different children.

b) Consideration of siblings of the ill or disabled child
Parents' attention and child-care energy are often centered on their ill or disabled children, resulting in less involvement with the child's siblings if present. For parents, the documentation of a healthy child's development often comes secondary to that of the ill or disabled child; however, the parent-child relationship is equally important for all children. Our system is designed to reduce these undesirable and unintended consequences. Disabilities may exist even in seemingly healthy siblings without yet having obviously manifested. Our system may therefore be an effective preventative tool for latent cases.

It Provides a Way for Parents to Convey as Much Information as Accurately as Possible to Health Professionals

Function 5 also falls under this healing. The application assists parents in communicating as much information as possible to medical staff.

Function 6:The date, time and specific items are easily input with a single tap: This simplified method of data input promotes utilization by parents and ensures the accumulation of information.

Function 7: Video is stored in chronological order, enabling users to grasp the child's condition in a time-dependent manner: The portability and simplicity of the information presentation will facilitate the review of the chronologically documented data according to the specific purpose. Even when parents fail to provide to-the-point explanations, "Mamin" can help specialists obtain whatever information they may need. Health specialists may ask the parents to document whatever information or video they feel to be necessary by their next visit. Parents can also append audio comments to each video screen if they have any relevant questions or complaints.

Function 8:The use of micro-SD card facilitates editing and organizing documented data on a computer screen: This helps both parents and health-care workers preserve the data contained in the application, either for creating a child-care album or for medical record-keeping.

It Facilitates Parents' Preparation, Helping Them Notice Even Slight Signs of Illness and/or Disability in Their Child and to Accept Reality

The details are as indicated in Functions 1, 2, and 4. The application encourages parents not to overlook even the slightest of signs and to be prepared to accept reality.

Function 9: Chronologically documented information enables parents to readily review the growth and development of their children: A characteristic of note with "Mamin" is that the recordkeeping is performed by the parents themselves, meaning that all documentation is the parents' responsibility. Forced acceptance of reality by others may result in parents' denial. "Mamin" therefore encourages parents' self-paced, step-by-step learning and acceptance of their children's illnesses and disabilities. 


\section{WHAT CAN NURSES EXPECT WITH "MAMIN"? |}

Figure 1 shows the structural framework for the early detection and diagnosis of illnesses and disorders using "Mamin". Nurses are medical professionals responsible for the early detection and intervention of ill and disabled children. Midwives are involved with ill or disabled children in the pre-and post-natal stages, while nurses' involvement starts from the neonatal intensive-care unit (NICU) and continues through infants' regular health check-ups. The smooth and prompt acceptance of reality and a positive attitude by parents are crucial for ensuring a good prognosis of the illness or disability following its detection and diagnosis. Nurses are expected to contribute to the early parental recognition and acceptance of the illness or disability by sharing timely information among themselves and in collaboration with other health-care workers.

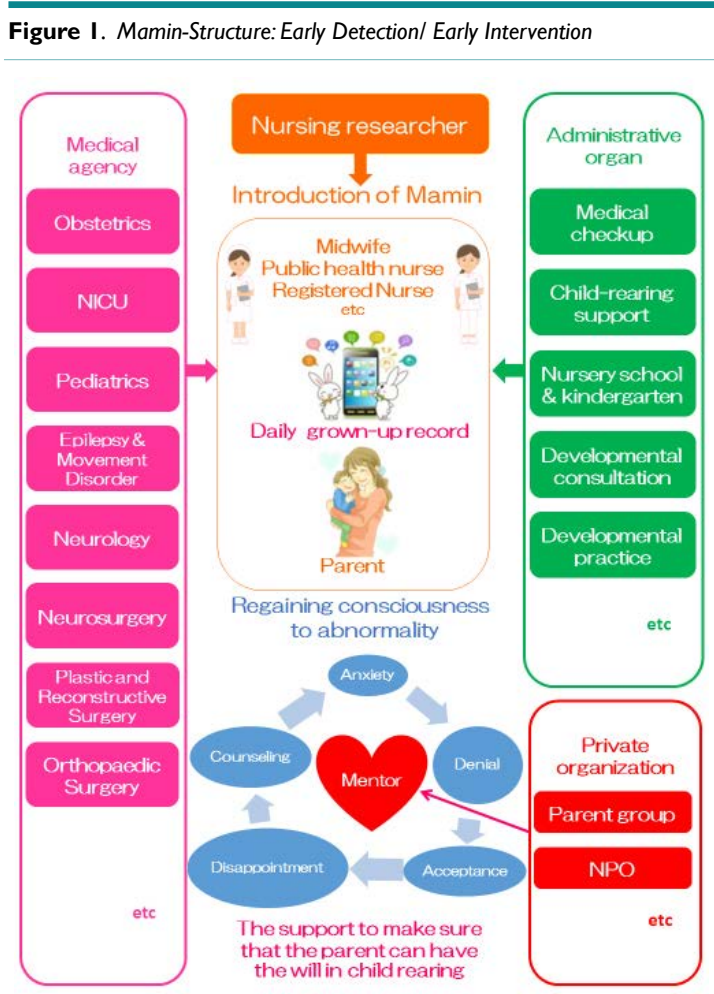

The availability and the future prospects for "Mamin" have been described. We must note that our written explanations on these points to parents do not include the expression 'early de- tection of illnesses or disorders', but instead 'child-care recordkeeping application'. We emphasize the close observation and recording of the child's growth and development, rather than the 'detection of illnesses and disabilities'. However, as time passes, the risk of illness or disability will inevitably increase. In such cases, "Mamin" can provide useful data enabling their early detection. This perspective differentiates "Mamin" from many other childgrowth application systems that have been developed in recent years. This kind of sensitive stance may reduce parents' resistance and hesitation to face reality, which eventually leads to the early detection of illness or disability and therefore the best developmental outcome possible.

\section{ACKNOWLEDGMENTS}

This work was supported by a Japanese Grant-in-Aid for Scientific Research - KAKENHI - , No.25463498.

\section{CONFLICTS OF INTEREST}

The authors declare no conflicts of interest in association with the present study.

\section{REFERENCES}

1. Olliac B, Crespin G, Laznik MC, et al. Infant and dyadic assessment in early community-based screening for autism spectrum disorder with the PREAUT grid. PLoS One. 2017; 12(12): e0188831. doi: 10.1371/journal.pone.0188831

2. Tachibana T, Miyazaki C, Ota E, et al. A systematic review and meta-analysis of comprehensive interventions for pre-school children with autism spectrum disorder (ASD). PLoS One. 2017; 12(12): e0186502. doi: 10.1371/journal.pone.0186502

3. Al Mamun KA, Bardhan S, Ullah MA, et al. Smart autism - a mobile, interactive and integrated framework for screening and confirmation of autism. Conf Proc IEEE Eng Med Biol Soc. 2016; 989-5992. doi: 10.1109/EMBC.2016.7592093

4. Spittle AJ, Olsen J, Kwong A, et al. The baby moves prospective cohort study protocol: Using a smartphone application with the general movements assessment to predict neurodevelopmental outcomes at age 2 years for extremely preterm or extremely low birthweight infants. BMJ Open. 2016; 6(10): e013446. doi: 10.1136/ bmjopen-2016-013446 